\title{
The Effects of Education on Tolerance: Research of Students' Social and Ethnic Attitudes
}

\author{
Baklashova T.A. ${ }^{a}$ \\ Galishnikova E.M.' \\ Khafizova L.V.c \\ a bc Kazan Federal University, Institute of Management, Economics and Finance, Kazan, 420008, Russia \\ Email: ptrlilia2004@mail.ru
}

\section{Doi:10.5901/mjss.2015.v6n1s3p335}

\begin{abstract}
The paper considers the concept of tolerance in different scholars' works and applies it to determine the notion for the Russian educational environment. Tolerance is viewed as a quality of a person which firstly is formed in the course of socialization throughout life and manifests itself in various fields. A significant role of education, combined with sports and social events in the personality development of each participant of the process is proved. Ethnic, social and personal tolerance were studied and analyzed.
\end{abstract}

Keywords: tolerance, toleration, personal, ethnic and social tolerance.

\section{Introduction}

It is universally known that the future of any country lies in the hands of today's young people. Therefore, the purpose of the youth training and education is to teach them to get along with each other, to understand human diversity, to be aware about social problems and improve behaviors that counteract those problems. In 1995, the UN adopted the "Declaration of Principles on Tolerance," which reveals the essence of the key concepts of human relationships tolerance [Declaration of Principles on Tolerance, 1995].

Tolerance is a term that means respect for different views and beliefs, behaviors and practices. Tolerant person usually exudes confidence, he/she is tolerant to other points of view, takes a proactive stance. Steven A. Weldon [Weldon, 2006] considers that "Tolerance ... is a fundamental principle of the liberal democratic creed. It requires citizens to uphold and secure the rights of groups, even those they find objectionable, to participate fully in political, social, and economic life".

Tolerance issue was considered by many scholars in different time periods from different perspectives: J. Himelhoch [. Himelhoch, 1950], P. Terenzini, A. Cabrera, Colbeck, C., Bjorklund, S., Parente, J. [Terenzini etc., 2001], Henderson-King D., Kaleta, A. [Henderson-King, 2000], Brown W. [Brown, 2006], Hogg M [Hogg, 2001]. Skiba P. and Simmons A. [Skiba, 2008] pointed out that the disproportionate representation of minority students in special education programs has its roots in a long history of educational segregation and discrimination. We should note Henderson-King D. and A. Kaleta's [Henderson-King, 2000] point of view on the understanding of tolerance. In their research they examine the effect that diversity-related courses and campus organizations have on students' intergroup tolerance and sociopolitical beliefs. Their findings indicate that such undergraduate experiences can buffer students from declines in intergroup tolerance that are exhibited among the general student population.

All the above mentioned notions that have found their rightful place in the "Declaration of Principles on Tolerance"[Declaration of Principles on Tolerance, 1995] and in some researches, we have combined in one notion that reveals our understanding of the essence of the concept under consideration - fundamental human rights, the dignity and worth of the human person, respect, acceptance and appreciation of the variety of cultures, respect for different views and beliefs, behaviors and practices, experience of living in deeply divided society or multicultural one, participation in political, social, and economic life.

Furthermore there are a number of opinions which express the interrelatedness of the tolerance concepts and identity. For example, for Brown W. [Brown, 2006] the main question of her book is how "tolerance talk" as she used to 
call it, turned into the beacon of multicultural justice and civic peace. Toleration, according to Brown, came to be linked to the politics of identity.

Yoonmi Lee [Lee, 2000] sees national identity in psychological terms as "an awareness of difference" - "a feeling and recognition of 'we' and 'they'". National identity is a person's identity and sense of belonging to one state or to one nation, a feeling one shares with a group of people, regardless of one's citizenship status. Lee Y. [Lee, 2000] cites the following: "The national education system came to assume a primarily responsibility for the development of the "nation", with spreading the standardized language, culture and a national identity. It helped to construct the "subjectivities of citizenship".

So the above researches have proved that a person's national identity results directly from "common points": multicultural justice and civic peace; respect the right of the individual to preserve his or her identity, including nationality, name and family relations; self-esteem, self-consciousness; person's identity and sense of belonging to one state or to one nation, a feeling one shares with a group of people, regardless of one's citizenship status. Moreover, one should respect national symbols, language, culture, traditions [Kalganova, 2014]. The expression of one's national identity seen in a positive light is patriotism.

\section{Theory}

It is interesting to note Bernard William's idea concerning concept of tolerance understanding. Williams B., cited by Oberdiek H. [Oberdiek, 2001] holds that tolerance is impossible virtue because we are required to tolerate the intolerable. Moreover he stressed that "the practice of toleration will remain necessary for the indefinite future". According to B.Williams, tolerance, leads us to cross-national, cross-generation, cross-gender, cross-religious understanding, ...tolerance mandates cross- " $X$ " understanding, where " $X$ " is anything that leads to misunderstanding and enmity. As for the students they are well aware of racial, religious and social differences but we cannot say for sure that they are convinced in their views. We fully understand that intolerance surrounds society; it penetrates all spheres of social life, consequently, it may be rather difficult to monitor what is learned in a non-educational setting. That is why, it is important to teach tolerance because young people are aware of racial and gender differences since early age.

A study conducted by Bracy N. [Bracy, 2011] is to some extent in common with that of B.Williams. Bracy N. explores the student's attitude towards public high schools high-security environments employing police officers, security cameras, and metal detectors, as well as strict discipline policies to keep students in line. These changes undoubtedly influence the social climate of schools, yet Bracy N. emphasizes that it is very little known how students experience and perceive these measures. The scholar examines students' perceptions of high-security school environments and concludes that students express feeling powerless as a result of the manner in which their schools enforce rules and hand down punishments.

Many years of teaching experience, analysis of literature on studies in pedagogy and psychology allow to suggest that tolerance means worldview, lifestyle, self-esteem, behaviors and practices or traditions. Besides in a statement of tolerance education plays the important role.

Careful analysis of the Russian and foreign researches in the field of our interests, interviews and opinion polls conducted show that the most common areas of understanding of this phenomenon or the concept of tolerance are: religious tolerance, racial and ethnic tolerance, political tolerance, tolerance against persons with disabilities, gender tolerance and sexual orientation-tolerance, educational tolerance.

We understand "tolerance" as a quality of a person which, firstly, is formed in the course of socialization throughout life and manifests itself in various fields. Secondly, it is the quality of a person that is required as internal installation of each individual. In the third, it is the ability and talent of human empathy, complicity manifested in different situations in the culture while respecting the traditions of people of different nationalities and religion.

Analysis of the concept of "tolerance" actualizes the problem of the study of three types of tolerance: ethnic, social and tolerance as a personal trait (personal tolerance). Ethnic tolerance is an attitude to the "other" on the basis of their ethnicity. As for social tolerance, it is an effective interaction with the representatives of different social groups [Gorelova, 2014]. Tolerance as a personal trait (personal tolerance) includes primarily system of values where respect for the individual and the recognition of his/her rights and freedoms are of key importance.

The education sphere plays a significant role in the development of human contacts at all levels, in various aspects of human activity [Galishnikova (2014), Grigorieva (2014), Ismagilova, Polyakova (2014), Mardanshina, Zhuravleva (2014)]. Involving students in the learning process contributes to the development of the personality of each participant in the process, raising the level of general and professional culture, the disclosure of internal potential students, and, as a consequence, the formation of personal, ethnic and personal tolerance [Baklashova (2014), Zalyaeva, Solodkova (2014)]. 
By education we mean both training and education, securing the latter a leading role in the formation of a proper level of tolerance (low and high).

\section{Methods and Approaches}

Theoretical analysis, the investigation and synthesis of progressive pedagogical experience, observation, comparison, questionnaire, mental experiment.

\section{Results}

The research was conducted during January 2013 to September 2014 and consisted of the following stages:

1. Selecting 117 respondents from the students of the Kazan Federal University (first-year students, General Economics division, the Institute of finance and Economics) who were planning to participate in XIII World Student Games in Kazan (Universiade 2013, July 2013) as volunteers [Khusainova, Rahmatullina 2014].

2. Organization and testing of the selected experiment participants to determine the level of ethnic, social and personal tolerance (express questionnaire "Tolerance index" (G.U. Soldatova et al.), sociological indicators of social and ethnic tolerance, "Ethnic Affiliation" test (G.U. Soldatova, S.V. Ryzhova)). The test results were analyzed by quantity and quality.

Fig.1 Quantitative analysis of tolerance (first-year students) (117 respondents)(January 2013)

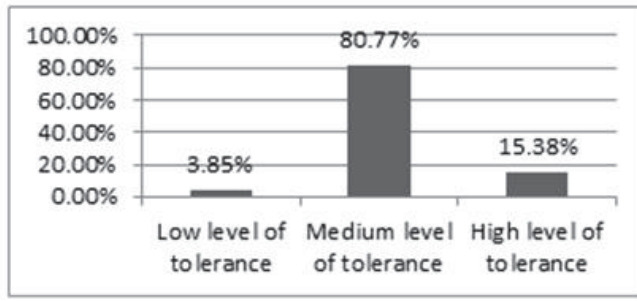

Fig.2 Qualitative analysis of tolerance (first-year students)(January 2013)

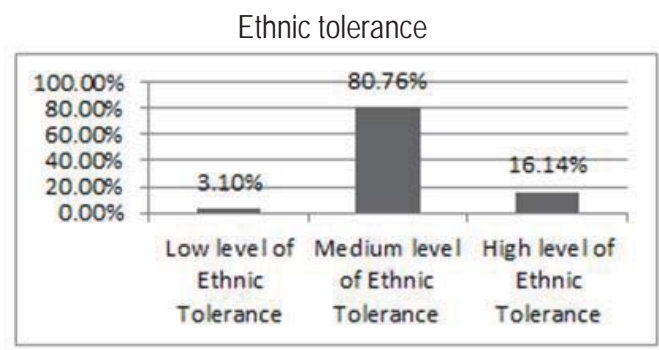

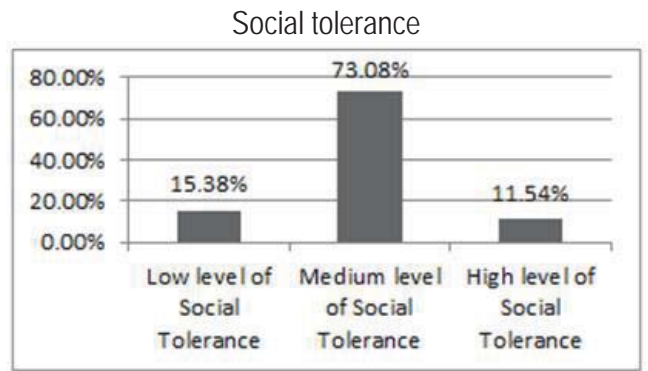


Tolerance as a personality trait

\begin{tabular}{|c|c|}
\hline $100.00 \%$ & $88.61 \%$ \\
\hline \multicolumn{2}{|l|}{$80.00 \%$} \\
\hline \multicolumn{2}{|l|}{$60.00 \%$} \\
\hline $40.00 \%$ & \\
\hline \multirow{4}{*}{$\begin{array}{r}20.00 \% \\
0.00 \%\end{array}$} & $8.66 \%$ \\
\hline & 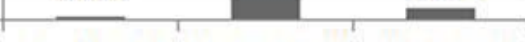 \\
\hline & $\begin{array}{l}\text { Low level of Medium level High level of } \\
\text { tolerance as a of tolerance as tolerance as a }\end{array}$ \\
\hline & $\begin{array}{ccc}\text { personality } & \text { apersonality } & \text { personality } \\
\text { trait } & \text { trait } & \text { trait }\end{array}$ \\
\hline
\end{tabular}

Control questionnaire of students (117 respondents) after their participation as volunteers in the Universiade 2013 (July 2013), as well as after holding International Youth Forum "Together we are strong!" (21-22 May, 2014, Institute of Economics and Finance, KFU) where an experimental group of students also participated (research and creative work implying intensive communication in the foreign language). The test results were analyzed by quantity and quality.

Fig.3 Quantitative analysis of tolerance (second-year students) (117 respondents)(September2014)

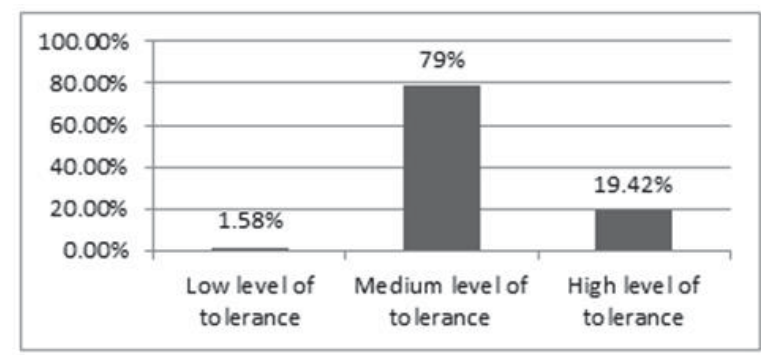

Fig.4 Qualitative analysis of tolerance (second-year students)(September 2014)

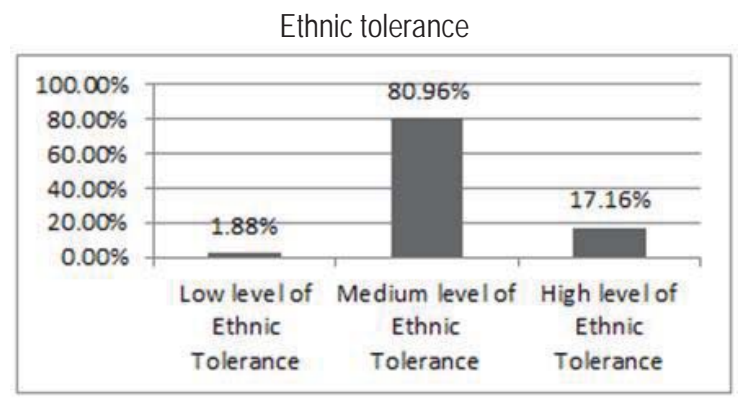

Social tolerance

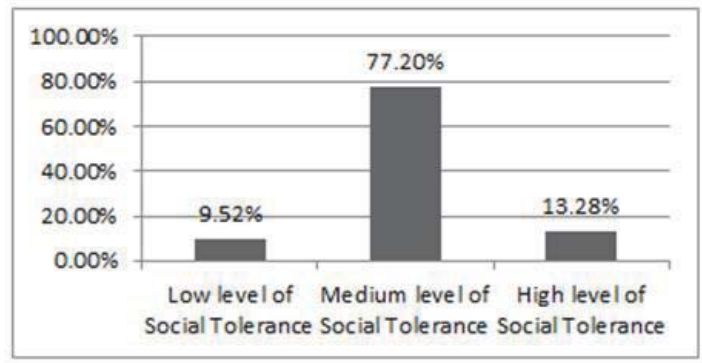


Tolerance as a personality trait

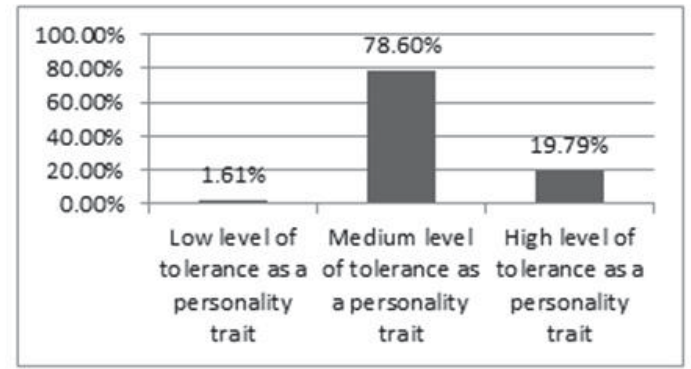

Changes in the tolerance level are presented in the tables.

Table 1. Change in the tolerance level of the students resulting from participation in sports and social events (quantitative analysis)

\begin{tabular}{|c|c|c|}
\hline Low tolerance level & Medium tolerance level & High tolerance level \\
\hline $\mathbf{- 2 . 2 7} \%$ & $-1.77 \%$ & $\mathbf{+ 4 . 0 4 \%}$ \\
\hline
\end{tabular}

Thus, quantitative analysis results in:

1) Negative dynamics of low tolerance index $(-2.27 \%)$

2) Positive dynamics of high tolerance index (+4.04\%)

Table 2. Change in tolerance level of the students resulting from participation in sports and social events (qualitative analysis)

\begin{tabular}{|l|c|c|c|}
\hline & Low tolerance & Medium level of tolerance & High level of tolerance \\
\hline Ethnic tolerance & $-1.22 \%$ & $+0.2 \%$ & $+1.02 \%$ \\
\hline Social tolerance & $-5.86 \%$ & $+4.12 \%$ & $+1.74 \%$ \\
\hline Tolerance as a personality trait & $-1.12 \%$ & $-10.01 \%$ & $+11.13 \%$ \\
\hline
\end{tabular}

Thus, the result of a qualitative analysis is the following:

1) Dominating of a negative dynamics of medium tolerance index on the "Tolerance as a personality trait" subscale (-10.01\%);

2) Dominating of a positive dynamics of high tolerance index on the "Tolerance as a personality trait" subscale $(+11.13 \%)$.

\section{Conclusion}

The study conducted with the use of variative techniques proves a significant role of education, combined with sports and social events in the personality development of each participant of the process. Results are the following: raising the level of general and professional culture, the disclosure of students' internal potential, and, as a consequence, the formation of personal, ethnic and social tolerance.

\section{References}

Baklashova,T. Manager's Professional Training in Russia: Syllabus and Technologies // Procedia - Social and Behavioral Sciences. Vol. 152, 2014. pp.1057-1061

Bracy, N. Student Perceptions of High-Security School Environments // Youth\&Society43(3), 2011. pp. 365-395

Brown, W. Regulating Aversion: Tolerance in the Age of Identity and Empire // The UK Princeton University press, 2006. p.268

"Declaration of Principles on Tolerance", 1995 (http://www.unesco.org/webworld/peace_library/UNESCO/HRIGHTS/124-129.HTM)

Galishnikova, E. Language Learning Motivation: A Look at the Additional Program // Procedia - Social and Behavioral Sciences. Vol. 152, 2014. pp.1137-1142

Gorelova, J. Advertising Language as a Means of Forming Students'Cross-cultural Competence // Procedia - Social and Behavioral 
Sciences. Vol. 152, 2014. pp.668-672

Henderson-King, D., Kaleta, A. Learning about Social Diversity: The Undergraduate Experience and Intergroup Tolerance // Journal of Higher Education71(2), 2000. pp. 142-64

Himelhoch, J. Tolerance and personality needs: A study of the liberalization of ethnic attitudes among minority group college students /I American Sociological Review, 1950. pp.79-88

Hogg, M. A Social Identity. Theory of Leadership Personality and Social Psychology Review. Vol. 5, No. 3, 2001. pp. 184-200

Ismagilova, L., Polyakova, O. The Problem of the Syllabus Design within the Competence Approach based on the Course "English for Master Degree Students in Economics (Advanced Level)" // Procedia - Social and Behavioral Sciences. Vol. 152, 2014. pp.10951100

Kalganova, G. Regional Languages in Economic Sphere in European Countries // Procedia - Social and Behavioral Sciences. Vol. 152, 2014. pp.1219-1224

Khusainova, A., Rahmatullina, A. English Language Training Volunteer Program as a New Reality for Russia and its Social Benefits // Procedia - Social and Behavioral Sciences. Vol. 152, 2014. pp.1101-1107

Lee, Yoonmi (2000). Modern Education, Textbooks, and the Image of the Nation: Politics and Modernization and Nationalism in Korean Education: 1880-1910. Routledge (published 2012). p. 29. ISBN 9781136600791. Retrieved 2013-12-01.

Skiba, P.J., Simmons, A.B. etc. Achieving Equity in Special Education: History, Status, and Current Challenges // Exceptional Children74(4), 2008. pp.264-288

Terenzini, P. T., Cabrera, A. F., Colbeck, C. L., Bjorklund, S. A., \& Parente, J. M. Racial and ethnic diversity in the classroom: Does it promote student learning? // Journal of Higher Education, 2001. pp.509-531

Weldon, S. The Institutional Context of Tolerance for Ethnic Minorities: A Comparative, Multilevel Analysis of Western Europe /I American Journal of Political Science50(2), 2006. pp.331-349

Zalyaeva, E., Solodkova, I. // 10. Teacher-student Collaboration: Institute of Economics and Finance Kazan Federal University Approach // Procedia - Social and Behavioral Sciences. Vol. 152, 2014. pp.1039-1044 